\title{
Visualization and Spatio-temporal Analysis of Tsunami Inundation: A Case of the Great East Japan Earthquake
}

\author{
Yuki Iwai \\ Graduate School of Life and Environmental Sciences, University of Tsukuba, 1-1-1, Tennodai, Tsukuba, Ibaraki 305-8572, Japan; \\ yiwai@geoenv.tsukuba.ac.jp
}

Keywords: Tsunami, Disaster, Great East Japan Earthquake, GIS, Spatio-temporal Analysis

\begin{abstract}
:
This study visualized the spatio-temporal changes in the tsunami inundation area and analyzed its expansion mechanism. The most characteristic of the Great East Japan Earthquake is the damage caused by the tsunami. And $90 \%$ of the dead was caused by it. One of the factors is that the preparation of countermeasures corresponding to the huge tsunami was not fully prepared. Therefore, after the Great East Japan Earthquake, the Japanese government has emphasized the importance of the advance preparation of the hugest tsunami expected. According to the past experience the occurring of huge tsunami is very rare. Earthquake researchers have observed same scale tsunami in every 1000 years in Japan. According prediction, next huge tsunami may be happened around the 2030. Therefore, analyzing the tsunami inundation mechanism of the Great East Japan Great Eastern is important for the future tsunami countermeasure. The arrival time and spatial distribution of tsunami inundation can be considered as a main important component of evacuation planning. In addition, a wide range of inundation area caused by huge tsunami is suitable for analyzing the inundation mechanism compared with a small-scale tsunami inundation. In this study I would like to examine the tsunami inundation process caused by the Great East Japan Earthquake in 2011.
\end{abstract}

The method is as follows. First, movies shooting the tsunami inundation are collected from DVDs and TV hosting services. And they are examined as analysis materials. As a result, movies that taken from the ground were impossible to shoot the dynamic process of tsunami flooding. So that movies that taken from the helicopter or airplane was selected in this research. Next, the movies are converted into images at regular intervals of time. And adding position information to images (geo-reference), images are imported on the geographic information system (GIS). After that, Inundation limit lines are digitized. In this study, inundation limit lines are created at intervals of around 5 seconds. However, when the image is disturbed by dust etc., images of around 5 seconds are used. Basic information on the tsunami inundation handled in this study is shown in Table 1 and Figure 1.



Figure 1. Study area. The red area is the analysis targeted area.

Created by GSI Maps and Google Earth. 
As the result, tsunami inundation process was strongly affected by the location of buildings (Figure 2). On the other hand, the inundation distance declined even where the fields spread. The spatio-temporal variation of the inundation process was quantitatively clarified. Regression analysis was performed with variables of inundation time and inundation distance. As a result, changes in correlation were observed in a certain section. In order to analyze the factors, two regression analyses were conducted. First is the inundation time and elevation as variables. Second is the inundation time and distance from buildings as variables. The building data had acquired the image before the earthquake (April 4, 2010) from Google Earth, and created the building shape data. As a result of each analysis, it became clear that sections where the elevation suddenly changes and the short distance from buildings, overlapped sections where the inundation distance does not extend (Figure 3). These results suggest that it is possible to predict inundation time and distance in other areas if parameters can be acquired.

Table 1. The information on the tsunami handled in this study.

Study area Sendai plain, Miyagi prefecture

Coastal landform

Shoaling beach

Maximum tsunami height $\quad 9.3 \mathrm{~m}$ (Natori and Yuriage area, from Tohoku Earthquake Tsunami Survey)

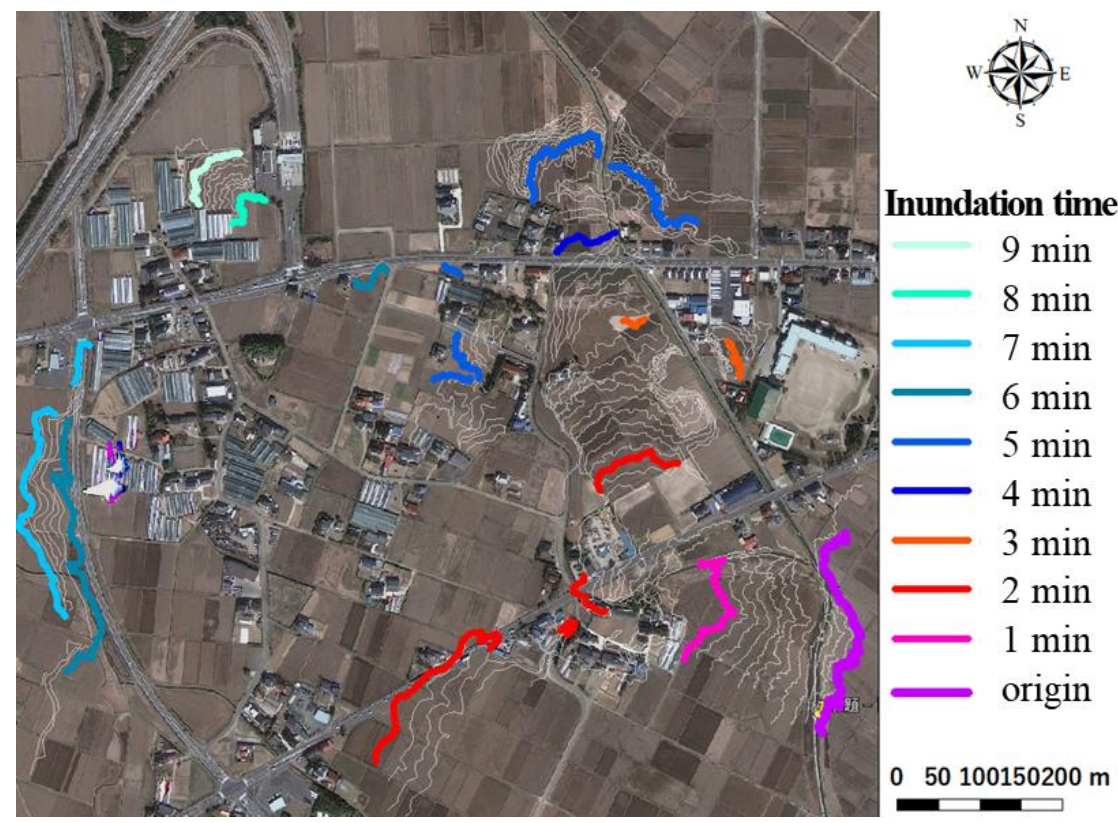

Figure 2. Spatio-tempral changes of the inundation process.
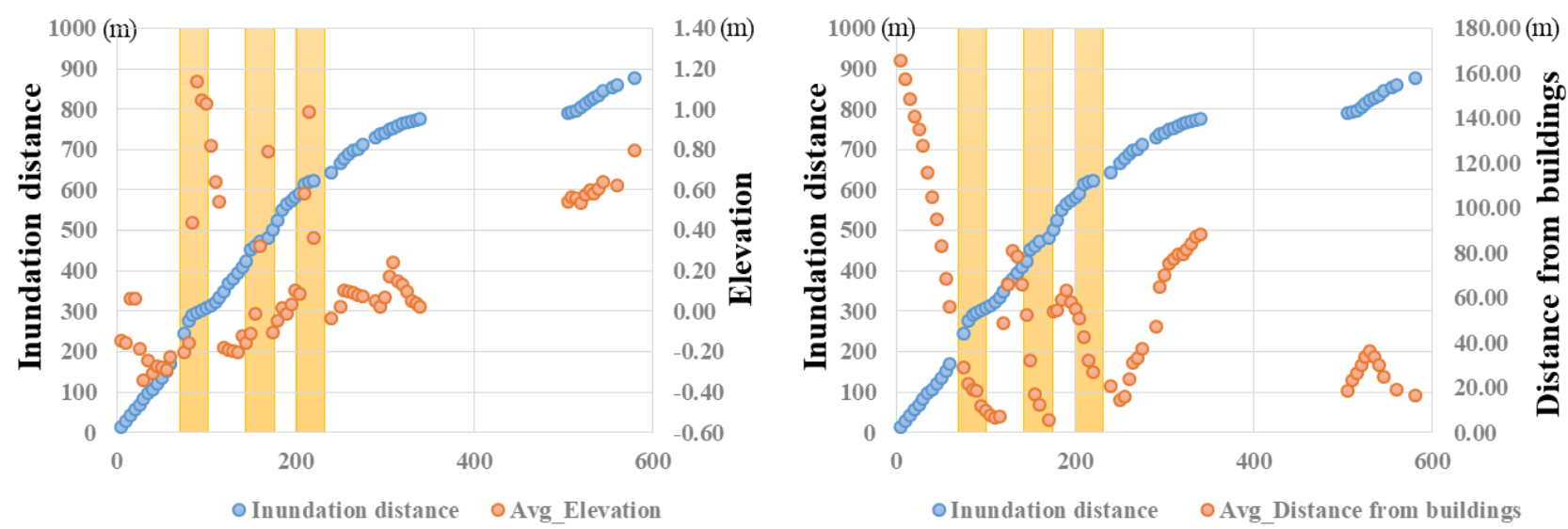

Figure 3. Correlation analyses of inundation distance and elevation (left) and distance from buildings (right). 